\title{
GCU
}

Glasgow Caledonian

University

University for the Common Good

\section{Top 10 research priorities relating to aphasia following stroke}

Franklin, Sue; Harhen, Dearbhla; Hayes, Michelle; McManus, Sasha Demos; Pollock, Alex

Published in:

Aphasiology

DOI:

$10.1080 / 02687038.2017 .1417539$

Publication date:

2018

Document Version

Author accepted manuscript

Link to publication in ResearchOnline

Citation for published version (Harvard):

Franklin, S, Harhen, D, Hayes, M, McManus, SD \& Pollock, A 2018, 'Top 10 research priorities relating to aphasia following stroke', Aphasiology, vol. 32, no. 11, pp. 1388-1395.

https://doi.org/10.1080/02687038.2017.1417539

\section{General rights}

Copyright and moral rights for the publications made accessible in the public portal are retained by the authors and/or other copyright owners and it is a condition of accessing publications that users recognise and abide by the legal requirements associated with these rights.

Take down policy

If you believe that this document breaches copyright please view our takedown policy at https://edshare.gcu.ac.uk/id/eprint/5179 for details of how to contact us. 


\title{
Top 10 research priorities relating to aphasia following Stroke
}

\author{
Abstract \\ Background \\ Pollock et al (2014) applied the James Lind Alliance methodology to derive the top 10 \\ priorities for research relating to life after stroke. Many of the initial Treatment \\ Uncertainties related to aphasia.
}

\section{Aim}

The current study uses these Treatment Uncertainties to derive the shared top 10 research priorities of people with aphasia (PWA), their carers and speech and language therapists (SLTs)

\section{Method}

Treatment Uncertainties relating to aphasia were identified from the 226 unique unanswered questions relating to life after stroke generated by Pollock et al. Using these 34 Treatment Uncertainties relating to aphasia, the last two stages of the JLA method (survey followed by consensus meeting) were carried out with PWA, their carers and SLTs. Participants ranked the top ten priorities from the 34 given in the survey.

Communication ramps were used with the PWA. The 16 highest ranked uncertainties were presented at the consensus meeting, where the final shared top 10 priorities were agreed, merging some statements and refining the wording in others.

\section{Results}

Participants included PWA with severely affected communication. The methodology produced consensus on a range of priorities including the best treatments and most effective service delivery, management of psychosocial issues, helping volunteers and carers and research into treating severe forms of aphasia.

\section{Conclusions}

PWA are able to participate fully in research priority setting. These shared research priorities represent an excellent base for the development of clinically important research in aphasia, addressing issues which are of greatest importance to key stakeholders.

Keywords: aphasia, research priorities, stakeholders, therapy, stroke 


\section{Introduction}

Traditionally, the subject of medical research is determined by academics and funding bodies, independent of patients and clinicians. PWA have not only been excluded from the process of deciding what is important in terms of research, but have even been omitted from the research itself. Although around a third of stroke survivors are PWA, research studies on stroke often specify communication disorder as an exclusion criterion: for example, 10 of 14 RCTs of depression rates in stroke specifically omitted PWA (Townend, Brady and McLaughlan, 2007) possibly resulting in a significant underestimate of the prevalence of depression. Brady, Fredrick and Williams (2013) concluded: "Generalized exclusion of people with aphasia ... has severe consequences for the accessibility of stroke treatment and care for this group of patients" (Page 195). If PWA are excluded from research, then it is unlikely that service provision will explicitly include them and their particular requirements. There is also a danger that research most needed by PWA will not even be prioritised if researchers do not have any experience of working with this client group.

Increasingly, the importance of involving patients and other stakeholders in setting the research agenda is recognised (Partidge and Scadding, 2004) and a detailed methodology has been developed by the James Lind Alliance (JLA) to study a variety of health conditions (Cowan and Oliver, 2015) and used to study health conditions such as autism, dementia and Parkinson's Disease. This methodology involves forming 'Priority Setting Partnerships' of patients and clinicians, who together identify important research themes, termed 'Treatment Uncertainties'. Surveys are then used to rank these uncertainties (Interim Priority Setting), and a 'final top ten' is decided in a consensus meeting of stakeholders (Final Priority Setting).

Pollock et al (2014) used the JLA methodology to identify the top 10 research priorities relating to life after stroke. Their Priority Setting Partnership comprised stroke survivors, 
(including PWA), carers and health professionals. It identified 226 unanswered Treatment Uncertainties, which were reduced to 24 shared top priorities by the survey, from which the top 10 were agreed at a consensus meeting. Four of the 24 shared top priorities and three of the top 10 priorities related to communication difficulties. In addition, St George and Pollock (2012) noticed that a significant number of the other uncertainties related to aphasia.

\begin{abstract}
Aim
The aim of the current study was to identify the top 10 research priorities relating to long-term aphasia, using aphasia-related treatment uncertainties derived from the original Pollock et al life after stroke study priority setting project. The stakeholders in this case were restricted to PWA, their carers and speech and language therapists (SLTs).
\end{abstract}

\title{
Method
}

Ethical approval for the research was obtained from the University of Limerick Ethics Committee.

\section{Selecting 'aphasia' Treatment Uncertainties}

All 226 research uncertainties from the Pollock et al study were considered independently by three authors to identify uncertainties related to aphasia. There was a high level of agreement as to which uncertainties should be included (referring to aphasia or to communication) with the exceptions being two uncertainties which referred to difficulties in comprehension due to cognitive difficulties. Through discussion, it was agreed that these uncertainties should be retained. There were 34 aphasia-related questions selected for the final two stages of the JLA methodology: the survey and the consensus meeting. 


\section{Participants}

Survey: PWA had to be over 18 and have aphasia as a result of a stroke; no limit on severity was set. Carers and PWA were sourced through visiting 5 Aphasia Support Groups. At a meeting of each group the researchers gave a presentation about the project and then participants volunteered via a gatekeeper. Twenty-three PWA volunteered but two were not included because they had not had a stroke (one had had a traumatic brain injury and one had primary progressive aphasia). The electronic survey was piloted by 3 experienced SLTs. One hundred and three SLTs who worked with PWA were emailed via a university database and asked to complete the survey monkey. The first mail out attracted 24 responses ( 6 of which were excluded because they had been filled in incorrectly). Further responses were not sought because it was felt that there should not be more SLT than PWA respondents.

Consensus meeting: SLTs working in Galway and Clare were invited to take part. PWA and carers were sourced through local groups. The PWA had to be able to travel to the meeting venue. The carers who attended the groups were all accompanying a PWA.

\section{Survey}

A survey was constructed for participants to rank the top 10 Treatment Uncertainties in order of importance. Three versions were prepared: an electronic survey for SLTs, a hard copy for carers and an aphasia friendly version completed by the PWA with SLT assistance. Forty-six participants responded to the survey, 21 PWA, 18 STLs and 7 carers.

Rankings were summed for all survey respondents and used to identify the top shared priorities for the final consensus meeting. We aimed to identify the top 15-20 priorities, as recommended by JLA.

\section{Consensus meeting}

This meeting is seen as an opportunity for different parties to express their views, hear different perspectives and think widely about treating or helping people with the condition at issue. An 
initial powerpoint presentation by the first author explained the format and purpose of the meeting. Three groups, each comprising PWA, carers and SLTs, studied the uncertainties and sorted them into 'important', 'not important' and 'not sure' categories. The uncertainties were each written on a card with pictures indicating aspects of the meaning and where the uncertainty was quite complex it was written in simpler language on the obverse. Each group was facilitated by an SLT who agreed rules for the group, for example that each individual would be given a chance to contribute and that adequate time would be given for all responses. Each group was encouraged to combine similar uncertainties, add any missing themes and finally select their top 10 and rank them. During a coffee break the three groups' edited uncertainties and their rankings were combined. In a final plenary session, the top 10 were presented to all participants. Following further discussion, the final wording and rankings were agreed.

\section{Results}

\section{Survey}

Eighteen SLTs, 7 carers and 21 PWA completed and returned the survey, giving a total of 46 participants. Based on their speech output, the PWA represented a spread of severity, 4 having mild aphasia, 11 moderate and 6 severe. One other PWA was unable to complete the survey because of fatigue. Communication ramps (for example pictures and expanded versions of the uncertainties) facilitated PWA in completing the survey.

Initially scores for the uncertainties were summed separately for the PWA, the carers and the SLTs, and the top ten choices for each group were considered (Appendix 1). All groups chose uncertainties around effective treatment and service delivery issues. Both the PWA and the SLTs selected mental health issues, but the carers did not. Both the PWA and the carers chose uncertainties around carers and caring, but the carers chose more of these. Only the SLTs 
chose uncertainties about the National Stroke Strategy, literacy and numeracy and return to work. Only the PWA selected an uncertainty about research on returning to driving.

A clear numerical break in the rankings led to the decision to select 15 uncertainties for the Final Priority Setting. However one further uncertainty (on 'driving') was added as this was the only uncertainty which was in the PWA's top 10 list but not in the shared top 15, giving 16 uncertainties in total (Table 1). These 16 uncertainties were taken forward to the consensus meeting.

Table 1 about here.

\section{Consensus meeting}

Twenty-two participants attended the consensus meeting: 10 PWA, 3 carers and 9 SLTs. The SLTs included hospital and community therapists. The PWA differed in severity of their aphasia (including at least one individual with Wernicke-type aphasia) and age (48-91 years). The PWA, carers and SLTs were distributed equally among the three groups, with one group being assigned one extra SLT. Carers were in the same group as their partner; although this could have constrained expression of opinion, it was decided that allowing the pair to stay together potentially facilitated the PWA's communication. Each group had a facilitator, an experienced speech and language therapist, who ensured that each group member had their say on each decision and used communication ramps where necessary for the PWA.

There was general consensus regarding ranking and the refinements made to the uncertainties provided. No uncertainties were completely rejected; a number were combined. For example, all groups merged the service delivery uncertainties into a single priority. Two uncertainties around treatment efficacy were combined but it was decided to keep treatment of comprehension as a separate priority because it was felt that research was badly needed into 
severe aphasia. The uncertainties concerning depression were combined into a single priority combining both assessment and treatment. As a consequence of the plenary discussion 'understand the impact of aphasia on significant relationships' was added to the depression priority. In group discussion the PWA did not feel that 'panic' accurately described feelings around communication and so in the plenary session it was decided to change the uncertainty about managing feelings of panic when speaking, to a research priority around 'managing adverse feelings'. The four uncertainties concerning volunteers and carers were collapsed to two priorities, one concerning their efficacy and one on methods of interventions for carers. Table 2 shows the final priorities.

Table 2 about here.

\section{Discussion}

The top 10 research priorities relating to aphasia have been identified by key stakeholders. This project builds on the previous life after stroke research prioritisation project, and clearly defines the research questions which are considered of greatest importance to PWA, carers and SLTs. This top 10 ought to be used to influence future funding and research agenda, addressing what matters most to people affected by aphasia after stroke.

This study demonstrated that PWA are fully able to participate in research priority setting. All PWA of varying severity were able to complete the survey with support from the researchers, with just one abandoning the task through fatigue. The PWA, despite including both people with severe aphasia and poor language comprehension, were able to complete the consensus procedure successfully, through use of communication ramps and explicit discussion 
and agreement at the beginning of the group work as to how individuals' opinions were to be sought, respected and allowed time for.

Comparing the survey outcomes for the three different groups, PWA, carers and SLTs, some clear differences appeared. Although all three groups chose uncertainties around effective therapy and timing of treatment, the carers specifically rated effective treatment for severe aphasia highly. They also chose several uncertainties around how carers or volunteers could communicate effectively with PWA. It was interesting that the carers did not select uncertainties around PWA's depression or anxiety. Thus the uncertainties the carers chose were particularly reflective of their difficulty in communicating with their person with aphasia. The PWA chose the widest spread of themes in the uncertainties they chose, including the issue of driving. They clearly saw it as important to look at more encompassing research, not just research around communication. One thing they did not choose however was research around returning to work. One might speculate that so few PWA return to work (Graham, Pereira and Teasall, 2011) that it is considered an unattainable goal. However, it is more likely that many of those attending an aphasia group might already be of retirement age. The SLT group mainly chose uncertainties which reflected research areas which corresponded to the SLT remit; this may be reflective of the fact that 10/18 SLTs worked in the acute sector. They did however choose uncertainties around depression, which may reflect the increase in research and resulting awareness in this area (Townend, Brady and McLaughlan, 2007).

Regarding methodology, comparison of the priorities ranked after the survey with the final top 10 demonstrated the importance of the consensus meeting. The survey resulted in a set of priorities which were narrow in range, somewhat repetitive and rather inexact. The possibility for negotiation and discussion at the face-to-face meeting meant that more topics could be included, more exact wording could be formulated and an extra theme, the effect of aphasia on relationships, could be added. 
A limitation of the study were the small number of participants at the survey stage, with disappointingly few carers. Pollock et al (2014) also remarked on the small number of carers in their study. It was possible that by including a range of stakeholders that the responses of the PWA would be minimised in the final selection of priorities. However every effort was made to ensure that everyone contributed to the consensus meeting, and the one topic which had been shown to be important to the PWA, research on driving, was added to the topic list for the consensus meeting and indeed made it into the final top ten. Another possible limitation was the way that uncertainties taken from the original stroke study were limited to those concerning aphasia and communication. It could be the case, were a full James Lind Alliance protocol applied to aphasia, that research around topics out with aphasia and communication would be chosen.

Regarding the priorities selected, five addressed more effective rehabilitation. Understanding which treatments work best and knowing when/how much to intervene are difficult to ascertain from current research owing to the lack of agreed outcome measures in aphasia (Brady et al 2012); an expert panel is currently addressing this (Wallace, Worrall, Rose and Le Dorze, 2014). Two of these five priorities reflected the importance of developing treatments for severe communication disorder. One trial is currently registered to measure outcomes in treating depression in aphasia (Worrall, Brooke and Hudson, 2016) which was identified as another priority, and stakeholders felt further research into supporting carers and volunteers was warranted. Research around returning to driving was also important to PWA.

Using this methodology, rather than just "be researched", PWA were able to add their own knowledge, experience and perspective to "what should be researched." We believe that this is an important first step to ensuring that future aphasia research reflects what is important to those affected. 


\section{References}

Brady MC, Fredrick A, Williams B. (2013). People with aphasia: capacity to consent, research participation and intervention inequalities. Int J Stroke: 8: 193-196.

Brady MC, Kelly H, Godwin J et al. (2012). Speech and language therapy for aphasia following stroke. Cochrane Database of Systematic Reviews: Issue: 5.

Cowan K, Oliver S. (2003)The James Lind Alliance Guidebook. Available at http://www.jlaguidebook.org/, accessed 22 September 2015.

Graham, JR, Pereira, S and Teasell, R. (2011). Aphasia and return to work in younger stroke survivors. Aphasiology, 25 (8), 952-960.

Partridge N, Scadding J. (2004). The James Lind Alliance: patients and clinicians should jointly identify their priorities for clinical trials. Lancet: 364:1923-4.

Pollack A, St.George B, Fenton M, Firkins L. (2014). Top 10 research priorities relating to life after stroke - consensus from stroke survivors, caregivers, and health professional. Int $J$ Stroke: 9: 313-320.

St George B and Pollock A on behalf of the 'Life after stroke' priority setting partnership (2012). Communication after stroke: a top research priority for stroke survivors. Int J Stroke: 7 (supplement 2): 4 
Townend,E., Brady,M. and McLaughlan,K. (2007) "Exclusion and inclusion criteria for people with aphasia in studies of depression after stroke: A systematic review and future recommendations", Neuroepidemiology, 29(1-2), 1-17.

Wallace SJ, Worrall L, Rose T, Le Dorze, G. Measuring outcomes in aphasia research: A review of current practice and an agenda for standardisation. Aphasiology 2014: 28: $1364-1384$.

Worrall, L, Brooke, R and Hudson, K et al. Reducing the psychosocial impact of aphasia on mood and quality of life in people with aphasia. TRIALS, 2016: 17 Article Number: 153. 
Table 1. Sixteen research uncertainties selected for consensus meeting.

Is speech and language therapy helpful for patients more than 1 year after a stroke? How can carers be helped to communicate with someone with aphasia?

What is the best way to help people recover from aphasia?

What is the best way to improve understanding (cognition) after stroke?

What is the best way to diagnose and assess depression in people with aphasia following a stroke?

Which speech and language therapy treatments work best for aphasia?

What is the best way to help people with aphasia return to driving after stroke?

Can supported communication training for carers help prevent relationship breakdown?

What stimulation techniques are useful for enhancing the engagement of stroke patients with severe cognition and communication impairments?

Do communication aids and software packages improve communication in patients with aphasia?

What is the best way to treat depression in people with aphasia following a stroke?

Do social communication groups improve confidence in people with communication problems after stroke?

When is the best time after stroke to deliver speech and language therapy?

What is the best way to manage feelings of panic due to aphasia?

What is the best amount and intensity of speech and language therapy for aphasia?

Can trained volunteers and carers help improve communication after stroke? 
Table 2. Final top ten research priorities for people with aphasia.

\begin{tabular}{|l|l|}
\hline 1 & Which speech and language therapy treatments work best for aphasia? \\
\hline 2 & $\begin{array}{l}\text { Speech and language therapy for aphasia: how soon should it begin, how } \\
\text { intensive should it be and how long does it continue to be effective? }\end{array}$ \\
\hline 3 & $\begin{array}{l}\text { What is the best way to assess, diagnose and manage depression in people with } \\
\text { aphasia and to understand the impact of aphasia on significant relationships? }\end{array}$ \\
\hline 4 & Can trained volunteers and carers impact on communication? \\
\hline 5 & $\begin{array}{l}\text { Do communication aids and software packages improve communication in } \\
\text { patients with aphasia? }\end{array}$ \\
\hline 6 & $\begin{array}{l}\text { What are the best ways to manage adverse feelings caused by a communication } \\
\text { difficulty? }\end{array}$ \\
\hline 7 & What is the best way to improve understanding after stroke? \\
\hline 8 & $\begin{array}{l}\text { What stimulation techniques are useful for enhancing the engagement of stroke } \\
\text { patients with severe cognition and communication impairments? }\end{array}$ \\
\hline 9 & $\begin{array}{l}\text { How can carers and others be helped to communicate with someone with } \\
\text { aphasia? }\end{array}$ \\
\hline 10 & What is the best way to help people with aphasia return to driving after stroke? \\
\hline
\end{tabular}




\section{APPENDIX 1:}

\section{Survey results}

A: Top ten research uncertainties chosen by people with aphasia.

\begin{tabular}{|l|l|}
\hline 1 & Which speech and language therapy treatments work best for aphasia? \\
\hline 2 & When is the best time after stroke to deliver speech and language therapy? \\
\hline 3 & Is speech and language therapy helpful more than I year after a stroke? \\
\hline 4 & How can carers be helped to communicate with someone with aphasia? \\
\hline 5 & $\begin{array}{l}\text { Do slowing down, providing written material, allowing time for questions and } \\
\text { using conversation partners help improve communication with people with } \\
\text { aphasia? }\end{array}$ \\
\hline 6 & $\begin{array}{l}\text { What is the best way to improve the production of structured sentences in } \\
\text { people with aphasia? }\end{array}$ \\
\hline 7 & Can trained volunteers and carers help improve communication after stroke? \\
\hline 8 & What is the best way to manage feelings of panic due to aphasia? \\
\hline 9 & $\begin{array}{l}\text { What is the best way to help people with aphasia to return to driving after } \\
\text { stroke? }\end{array}$ \\
\hline 10 & What is the best way to improve understanding (cognition) after stroke? \\
\hline 10 & $\begin{array}{l}\text { What is the best way to treat depression in people with aphasia following } \\
\text { stroke? }\end{array}$ \\
\hline
\end{tabular}

B: Top ten research uncertainties chosen by carers.

\begin{tabular}{|l|l|}
\hline 1 & $\begin{array}{l}\text { Do slowing down, providing written material, allowing time for questions and } \\
\text { using conversation partners help improve communication with people with } \\
\text { aphasia? }\end{array}$ \\
\hline 2 & How can carers be helped to communicate with someone with aphasia? \\
\hline 3 & When is the best time after stroke to deliver speech and language therapy? \\
\hline 4 & What is the best way to help people recover from aphasia? \\
\hline 5 & $\begin{array}{l}\text { Do social communication groups improve confidence in people with } \\
\text { communication problems after stroke? }\end{array}$ \\
\hline 6 & Which speech and language therapy treatments work best for aphasia? \\
\hline 7 & $\begin{array}{l}\text { What stimulation techniques are useful for enhancing the engagement of stroke } \\
\text { patients with severe cognition and communication impairment? }\end{array}$ \\
\hline 8 & Can trained volunteers and carers help improve communication after stroke? \\
\hline 9 & $\begin{array}{l}\text { What is the best amount and intensity of speech and language therapy for } \\
\text { aphasia? }\end{array}$ \\
\hline 9 & $\begin{array}{l}\text { Is speech and language therapy helpful for patients more than 1 year after } \\
\text { stroke? }\end{array}$ \\
\hline 9 & Can transcranial magnetic stimulation help people with aphasia? \\
\hline
\end{tabular}

C: Top ten research uncertainties chosen by speech and language therapists.

\begin{tabular}{|l|l|}
\hline 1 & $\begin{array}{l}\text { What is the best amount and intensity of speech and language therapy for } \\
\text { aphasia? }\end{array}$ \\
\hline 2 & $\begin{array}{l}\text { Do communication aids and software packages improve communication in } \\
\text { patients with aphasia? }\end{array}$ \\
\hline 3 & When is the best time after stroke to deliver speech and language therapy? \\
\hline
\end{tabular}




\begin{tabular}{|l|l|}
\hline 4 & $\begin{array}{l}\text { Has the National Stroke Strategy impacted on the provision of services for } \\
\text { patients with long term communication problems following stroke? }\end{array}$ \\
\hline 5 & Which speech and language therapy treatments work best for aphasia? \\
\hline 6 & What is the best way to help people with aphasia return to work? \\
\hline 7 & $\begin{array}{l}\text { Do social communication groups improve confidence in people with } \\
\text { communication problems after stroke? }\end{array}$ \\
\hline 8 & Can cognitive behavioural therapy (CBT) help recovery of speech? \\
\hline 9 & Can Adult Education improve stroke acquired literacy/numeracy problems? \\
\hline 10 & $\begin{array}{l}\text { What is the best way to diagnose and assess depression in people with aphasia } \\
\text { following stroke? }\end{array}$ \\
\hline
\end{tabular}

